\title{
Problems Experienced by Adolescents with Autism Spectrum Disorder: Exploring Social, Educational and Economic Variables
}

Saeb K. Ellala ${ }^{+*}$ and Ola M. Abusukkar*

\section{Abstract}

The study investigates the problems of adolescents with Autism Spectrum Disorder (ASD) from the perspective of ASD specialists and adolescent's families. It comprises of 228 ASD specialists and 294 families of ASD adolescents. The sample represents all areas of the Kingdom of Saudi Arabia (henceforth - KSA): north, south, east, west and centre. Variables of the study are adolescents' gender, age, residential area, as well as the qualification of ASD specialists and family members. To accomplish the study, the researchers designed a questionnaire that includes variables regarding six significant problems: Educational, Recreational, Economic, Health, Psychological, and Social. The results reveal that families rate the economic problems higher than average, while the recreational ones - lower; specialists rate economic problems higher than average and educational ones - the lowest. As for gender variable, specialists and families note the differences in favour of females; for age variable, specialists and families note that 15-18 years old ASD adolescents have more problems. The results show that qualification of specialists as well as family members is of significant relevance in relation to ASD adolescents. Both specialists and family members are mostly from the central regions.

Keywords: Autism Spectrum Disorder (ASD); Adolescents; Autism Spectrum Disorder (ASD) Specialists; Family Members; Social and Economic Problems; Kingdom of Saudi Arabia

\footnotetext{
${ }^{+}$Department of Special Education, Princess Norah Bint Abdulrahman University, Saudi Arabia

${ }^{*}$ Corresponding Author, Email: saebellala25@gmail.com, skallala@pnu.edu.sa

* Department of Special Education, Princess Norah Bint Abdulrahman University, Saudi Arabia, Email: omabusukkar@pnu.edu.sa

(C) 2020 Ellala \& Abusukkar. This is an Open Access article distributed under the terms of the Creative Commons Attribution License (http://creativecommons.org/licenses/by/2.0), which permits unrestricted use, distribution, and reproduction in any medium, provided the original work is properly cited.
} 


\section{Introduction}

Adolescence is an important stage in human life; this stage is interspersed with significant emotional and physiological changes (Sawyer, Azzopardi, Wickremarathne, \& Patton, 2018). These changes affect the adolescent's behaviour and his/her interaction with family, friends, and society in general (Jiménez-Iglesias, Moreno, Ramos, \& Rivera, 2015). At this stage, an adolescent reaches emotional and intellectual maturity, his/her personality and self-perception are formed. Adolescence is one of the most critical stages of human development that affects all stages after it, and this stage becomes more difficult and complicated if the person has Autism Spectrum Disorder (ASD) (Chen, Lee, \& Lin, 2015). The life of adolescents with ASD becomes more difficult due to the lack of social interaction and communication.

ASD is a common neurodevelopmental disorder among children who exhibit challenging behaviours not only during childhood but also during adolescence and adulthood (Seltzer \& Krauss, 2002). It is noteworthy that there are no centres in KSA to treat such a group of patients, though the number of children who have ASD amounts to five hundred thousand. As a result, many families travel abroad to countries like Jordan and America for treatment. About five thousand students and children on scholarships have ASD. In compliance with KSA's Vision 2030 and The National Transformation Plan 2020, which provides for the empowerment of persons with disabilities, the Ministry of Labour and Social Development has ordered to cancel scholarships for young people with ASD and finance the relevant ASD services in KSA instead (Fakeeh, 2016). KSA runs short of essential services for ASD youth, and thus, it is necessary to develop new high-quality services in different centres and establishments (Alshuwaikhat \& Mohammed, 2017).

There are many $15-24$ years old youths with ASD in KSA. Due to this, the government is concerned with meeting their various needs (Qahtani \& Hiyasat, 2016). Youth is the period at which the childhood stage ends and maturity begins. It is easy to determine the beginning of adolescence, but it is challenging to determine its end. The beginning is determined by physical maturity, but the end of adolescence is determined by maturity in all aspects of development. Physical maturity is confined to sexual maturity (Fayyad, 2014). This stage has many characteristics, which constitute an additional challenge to family upbringing. One of those essential features is the emotional one that includes offending feelings, self-centredness, sentimental fluctuation, social isolation and surrealism.

Among the foremost social features is family isolation, earnest desire for teamwork, searching for an ideal, love of country and interest in the other sex, in addition to other physical and mental features (Centre for Adolescent Health, 2010). There is an increased urgency to meet the needs of the adolescent if he or she is disabled, and especially with ASD, when there is $63.5 \%$ of them over the age of 16 (Waznah, 2011).

The study of Kharaan (2016) was aimed to identify the behavioural problems faced by children with ASD as well as present ways for families to deal with such problems. The results showed that social interaction problems rated the highest, while self-injury got the lowest. The study also showed that there were no statistically significant differences regarding the academic qualification of the family members, family income, or gender of ASD children. The results showed statistically significant differences among ASD children's problems due to the child's age change. The study of Fayyad (2014) aimed to detect the problems of mothers of adolescents with ASD and Down syndrome and ordinary adolescents. Mothers of ASD adolescents encountered the most critical problems, namely, economic, emotional, health, followed by family problems and social ones. Most problematic adolescents are as follows: adolescents with ASD followed by ordinary adolescents and, finally, Down syndrome adolescents. In addition, male adolescents faced more problems than female ones. The aim of the study of Zaghareer (2009) was to trace sources of psychological pressures as well as develop 
coping strategies for ASD adolescents' families in Jordan. The study showed that the most common sources of pressure were thoughts about future, anxieties, inability to bear the child's burdens, indecent self-performance, cognitive and psychological problems, and finally family problems.

This study aims to determine the various significant problems that ASD adolescents (of both sexes) encounter, whether those problems are social, educational, psychological, recreational, or medical. The families of adolescents with ASD are studied at different levels: economic, social, educational. Families of ASD adolescents and ASD specialists from northern, southern, western, eastern and central regions of KSA are considered. The researchers consider the theoretical statements of the life of adolescents with ASD becomes as well as the issues of social interaction and communication. The study begins with a description of the research design and other methodological issues that have been applied in the research. This follows a critical analysis and discussions of the results of the study.

\section{Methods}

\section{Research Design}

The descriptive-analytical method was used to determine the problems faced by ASD adolescents from the perspective of ASD specialists and adolescents' families. The study covered cities from north, south, west, east and centre of the KSA.

\section{Research Sample}

The study sample consisted of 228 specialists ( 71 males and 157 females with the following academic qualification: BA - 93, MA - 52, PhD 83) working with ASD adolescents. The sample also included adolescents' families (294 - 128 males and 166 females; secondary qualification 97, BA - 100, MA - 97) in 2018. The study instrument was distributed electronically and in the paper in the areas where the research was conducted.

\section{Instruments of the study}

The researchers developed a new instrument to measure the problems of adolescents with ASD. That instrument consisted of two parts, the first of which included basic variables of the study such as: gender, qualification, residential area and age, the second included items covering the problems that the adolescents encounter in six fields: social, psychological, economic, educational, recreational, and health.

Diagnosis of autism by specialists has been carried out using a test PEP (Psychoeducational Profile), as well as using a test Autism Diagnostic Interview - ADI-R, which is one of the best tests to identify possible deviations in behaviour and the level of mental development of the child. The first part of the survey has been conducted with parents of autistic children according to generally accepted method ATEC (Autism Treatment Evaluation Checklist), which includes four blocks:

- sociability, level of development of speech and language;

- child socialisation level;

- level of sensory skills of the child and his/her interest in the outside world (cognitive abilities);

- the level of health and physical development of the child. Each block has 17-22 questions with 3-5 answer options.

The second part of the survey of parents has been conducted according to the standard method Autism Diagnostic Parents Checklist ADPC. It included blocks with information on the social status of the family, the level of education of the parents, the general health level of all family members, as well as information on leisure activities (outdoor activities, nature trips, tourism) conducted by autistic child's family. In the second part of the questionnaire, the parents answered the following questions:

- When did you first start worrying about your child's development?

- At what age did your child receive the first ASD medical help?

- What was the diagnosis of a doctor specialising in autism and how many times did you visit such specialists? 
- Did the subsequent types of therapy correspond to the diagnostic process?

The questionnaire consisted of 130 questions, mainly devoted to identifying the level of parenting of autistic children: protection of the child, the satisfaction of his/her needs, upbringing - what can and cannot be done, what needs to be done, that is, requirements and prohibitions. Characteristics such as the level of cohesion and adaptation of the family were revealed.

\section{Ethical and Moral Standards}

The posed issues need to comply with ethical and moralally accepted standards. An agreement on anonymity and non-disclosure of information was concluded in writing with each of the parents or guardians or legal representatives of an autistic child. In the questionnaire, there were no questions about the names of each family, their exact place of residence, that is, that could affect the disclosure of the anonymity of the information provided. The study included only those families that gave written consent to conduct the survey. The methods of collecting information were consistent with ethical and moral standards related to the anonymity and non-disclosure of data.

\section{Measurement Correction}

Guardians' responses were distributed according to Likert scale (always, sometimes, rarely, never) and were given the following points $(5,4,3,2,1)$. Accordingly, the total marks of the scale ranged 38-190 and were divided into three categories: high, medium, and low-level problems. Thus, problems were as follows:

- High-level problems (3.68 - 5);

- Medium problems (2.34-3.67);

- Low problems $(1-2.33)$

\section{Validity of the Instrument}

To verify the validity, the instrument was presented to 10 specialists from the following universities: Noura, Najran, King Saud and Tabuk to check the suitability of the items. Specialists agreed that $85 \%$ of the items were relevant, and the rest had to be rejected.

\section{Reliability of the Instrument}

To verify the reliability of the instrument, the researchers adopted the Cronbach Alpha Coefficient. The values ranged 0.799-0.898, while the reliability coefficient was 0.844 , indicating a high level of validity. The values of the validity coefficient pertaining problems of adolescents with ASD from the perspective of specialists and families were as follows: social problems - 0.799; psychological - 0.808; economic problems - 0.827; educational - 0.877; recreational -0.856 . These results show that the scale used to measure adolescents' problems is reliable and can be used.

\section{Limitations of the Study}

The study is limited to males and females aged $12-18$ years adolescents from KSA. The study is limited to several locations in the KSA where adolescents with ASD live. The study is also limited to problems like educational, social, medical, psychological and recreational.

\section{Results}

Table 1 shows that the general average of the problems is 115.63 . It also shows that the economic problems rate the highest with arithmetic mean 3.86, followed by social problems (3.75). The recreational problems are the lowest with arithmetic mean 2.94. The males are given a better chance than females to practice sport. Health problems rate fourth. Few families remain aware of their adolescents' health conditions. The educational problems occupy fifth position. The statement that adolescents have adequate basic educational skills (reading, writing, arithmetic) has a high rate, while that about providing adolescents with adequate governmental services rates the lowest. The study finds that gender plays a significant role, from the perspective of both specialists and families. 
What are the Problems of ASD Adolescents in KSA from the Perspective of Families?

\begin{tabular}{|c|c|c|c|c|c|c|}
\hline Problems & $\begin{array}{l}\text { Number } \\
\text { of Families }\end{array}$ & Total & $\begin{array}{l}\text { Arithmetic } \\
\text { Mean }\end{array}$ & $\begin{array}{l}\text { Standard } \\
\text { Deviation }\end{array}$ & Average & Rate \\
\hline Social & 294 & 5241 & 17.83 & 4.12 & 3.75 & 3 \\
\hline Psychological & 294 & 5480 & 18.64 & 4.19 & 3.73 & 2 \\
\hline Economic & 294 & 6804 & 23.14 & 4.36 & 3.86 & 1 \\
\hline Educational & 294 & 5219 & 17.75 & 6.00 & 2.96 & 5 \\
\hline Recreational & 294 & 5183 & 17.63 & 6.14 & 2.94 & 6 \\
\hline Health & 294 & 6068 & 20.64 & 4.68 & 3.44 & 4 \\
\hline Total & 294 & 33995 & 115.63 & 22.61 & & \\
\hline
\end{tabular}

Source: elaborated by the authors

What are the Problems of ASD Adolescents in KSA from the Perspective of Specialists?

\begin{tabular}{|c|c|c|c|c|c|c|}
\hline Problems & $\begin{array}{l}\text { No. of } \\
\text { Specialists }\end{array}$ & Total & $\begin{array}{l}\text { Arithmetic } \\
\text { Mean }\end{array}$ & $\begin{array}{l}\text { Standard } \\
\text { Deviation }\end{array}$ & $\begin{array}{l}\text { Average } \\
\text { out of } 5\end{array}$ & Rate \\
\hline Social & 228 & 3988 & 17.49 & 3.63 & 3.50 & 3 \\
\hline Psychological & 228 & 4268 & 18.72 & 3.92 & 3.74 & 2 \\
\hline Economic & 228 & 5191 & 22.77 & 4.23 & 3.80 & 1 \\
\hline Educational & 228 & 4021 & 17.64 & 6.02 & 2.94 & 6 \\
\hline Recreational & 228 & 4037 & 17.71 & 6.21 & 2.95 & 5 \\
\hline Health & 228 & 4669 & 20.48 & 4.50 & 3.41 & 4 \\
\hline Total & 228 & 26174 & 114.80 & 22.22 & & \\
\hline
\end{tabular}

Table 2 shows that the general average of the problems is 114.80 . It also shows that economic problems occur at the top-the highest with arithmetic mean 3.80 , followed by psychological problems (3.74); the rate of the educational problem is low with arithmetic mean 2.94.

\section{Do Problems of Adolescents with ASD Differ} with Relation to Gender (from the perspective of Specialists and Families)?

T-test was used for the independent samples to find the differences between the two means. The arithmetic mean for males is 106.65 , while for females it is 118.48 with -11.83 difference. Degree of freedom is 226 and T-value -3.877. As the statistical significance is 0.000 , which is less than 0.05 , the differences between the means of males and females are statistically significant in favour of females. To determine the problems faced by adolescents with ASD, the researchers got the final count for the responses of every one of the family to get the arithmetic mean and standard deviation of these answers. T-test was used afterwards for the independent samples to determine differences between the two means.

The arithmetic mean for males is 107.79 while for females, it is 121.64 with -13.80 difference. The degree of freedom is 292, and calculated Tvalue is -5.436 . As the statistical significance is 0.000 , which is less than 0.05 , the differences between means of males and females are with statistical significance from the perspective of families. The result proves that, in relation to gender, there are statistically significant differences $(a \geq 0.5)$ regarding the problems adolescents with ASD face, in favour of females. 


\section{Do Problems of Adolescents with ASD differ because of Age, from the Perspective of Specialists and Families?}

The researchers calculated the total answers of each specialist to determine the arithmetic mean and standard deviation using T-test for the independent samples to find out the differences between the two means.

The arithmetic mean for the first category is 108.18 , for the second it is 119.27 with -11.09 difference. The degree of freedom is 226 , and $T$ calculated value is -3.846 . As the statistical significance is 0.000 , which is less than 0.05 , the differences between the means of the first and second categories have a statistical significance in favour of the second. The arithmetic mean of the second category is 108.23 , for the second it is 124.71 with -16.48 difference. The degree of freedom is 292, and calculated T-value is -6.661 . As the statistical significance is 0.000 , which is less than 0.05 , the differences between means of the first and second categories are with statistical significance, which goes in favour of the second. There are differences with statistical significance $(a \geq 0.5)$ between adolescents with ASD regarding age from the perspective of specialists and families. This indicates that the older an adolescent with ASD is, the more problems he/she faces.

\section{Do Problems of ASD Adolescents Relate to the Academic Level of Specialists?}

The researchers analysed specialists' answers and calculated the arithmetic mean and standard deviation. Then one-way ANOVA was used to find the differences between the means. There are 93 specialists with BA with arithmetic mean 108.19 and standard deviation of 13.70. There are 52 MA specialists with arithmetic mean 106.94 and standard deviation of 14.18. Besides, there are $83 \mathrm{PhD}$ specialists with arithmetic mean 127.12 and standard deviation, 27.60 .

\begin{tabular}{|c|c|c|c|c|c|}
\hline $\begin{array}{l}\text { Variance } \\
\text { Source }\end{array}$ & Total squares & $\begin{array}{l}\text { Degree of } \\
\text { Freedom }\end{array}$ & $\begin{array}{l}\text { Variance } \\
\text { Mean }\end{array}$ & $\begin{array}{l}\text { (F) Calculated } \\
\text { Value }\end{array}$ & $\begin{array}{l}\text { Statistical } \\
\text { Significance }\end{array}$ \\
\hline $\begin{array}{l}\text { Between } \\
\text { groups }\end{array}$ & 19868.581 & 2 & 9934.291 & 24.843 & 0.000 \\
\hline Inside groups & 89972.138 & 225 & 399.876 & & \\
\hline Total & 109840.719 & 227 & & & \\
\hline
\end{tabular}

Table 3 shows 19868.581 squared deviations between groups, inside the groups, there are 89972.138. Degree of freedom between groups is 2 , and 225 - inside groups. The variance means between groups are 9934.291 and 399.876 inside groups. The calculated (F) value is 24.843 . As for the statistical significance, it is 0.000 , which is less than 0.05, indicating that differences between means of specialists at all levels are with statistical significance.

The differences with statistical significance of specialists' means are due to the difference between BA and PhD. The difference between the two means is -18.92693 , and the statistical significance is 0.000 , which is less than 0.05; the difference between the means of MA and PhD is -20.17817 . The differences between other means are of no statistical significance.

There are 97 family members with secondary education, their arithmetic mean is 108.28 , and the standard deviation is 13.53 . There are 100 BA specialists, their mean is 107.07, and the standard deviation is 15.85 . As for MA, there are 97 family members, their mean is 131.80 , and the standard deviation is 26.61 .

Table 4 shows that the total square deviations between groups are 37945.316 and 111865.273 inside groups. Freedom degrees between groups are 2 and 291 - inside groups. The variance mean between groups is 18972.658 and 384.417 - inside groups. The calculated (F) value is 49.354 . As for the statistical 
significance, it is 0.000 (less than 0.05), which indicates that there are statistically significant differences between members of the family in relation to academic levels. To determine sources of those differences, the researchers applied Chavez post comparisons.

The statistically significant differences are due to the difference between secondary and higher

\section{Table 4: Results of one-way ANOVA}

\begin{tabular}{l|l|l|l|l|l|}
\hline $\begin{array}{l}\text { Variance } \\
\text { Source }\end{array}$ & $\begin{array}{l}\text { Square Total } \\
\text { Between }\end{array}$ & $\begin{array}{l}\text { Freedom } \\
\text { Degree }\end{array}$ & $\begin{array}{l}\text { Variance } \\
\text { Mean }\end{array}$ & $\begin{array}{l}\text { (F) Calculated } \\
\text { Value }\end{array}$ & $\begin{array}{l}\text { Statistical } \\
\text { Significance }\end{array}$ \\
\hline Inside groups & $\begin{array}{l}111865.273 \\
\text { Total }\end{array}$ & 291 & 18972.658 & 49.354 & 0.000 \\
\hline Tource: elaborated by the authors & 293 & 384.417 & \\
\hline
\end{tabular}

Do ASD Adolescents Face Different Problems in Different Areas of Living (from the perspective of specialists)?

Forty-seven specialists indicate the northern area as problematic, with arithmetic mean $108.72 ; 44$ - eastern, with a mean of $106.34 ; 47$ - southern, with arithmetic mean 106.89; 42 western, with a mean of 107.86; 48 - central, with a mean of 142.31 . The total deviation squares between groups are 46179.505 and 63661.214- inside groups. Freedom degrees between groups are 4 and 223 - inside. Results studies. The difference between the two means is -23.52577; the difference between BA and $M A$ is -24.73412 . The differences between means of the rest had no statistical significance. Thus, there are statistically significant differences in family members' academic level $(\alpha \leq 0.5)$ that relate to the problems of adolescents with ASD face.

\begin{tabular}{|l|l|l|l|l|l|}
\hline \multicolumn{3}{|l}{ Table 5: Results of One-way ANOVA } \\
\hline $\begin{array}{l}\text { Variance } \\
\text { Source }\end{array}$ & Total Squares & $\begin{array}{l}\text { Freedom } \\
\text { Degree }\end{array}$ & $\begin{array}{l}\text { Variance } \\
\text { Mean }\end{array}$ & $\begin{array}{l}\text { F Calculated } \\
\text { Value }\end{array}$ & $\begin{array}{l}\text { Statistical } \\
\text { Significance }\end{array}$ \\
\hline $\begin{array}{l}\text { Between } \\
\text { groups }\end{array}$ & 20985.441 & 4 & 5246.360 & 11.769 & 0.000 \\
\hline Inside groups & 128825.147 & 289 & 445.762 & & \\
\hline Total & 149810.588 & 293 & & & \\
\hline Source: elaborated by the authors & & & & \\
\hline
\end{tabular}

Table 5 shows 20985.441 total square deviations between groups and 128825.147 inside groups; there are 4 freedom degrees between groups and 289 - inside groups. The Table also shows 5246.360 variance means between groups and 445.762 - inside groups. Calculated F-value is 11.769. As for the statistical significance, it is 0.000 (less than 0.05 ), which indicates that differences between show that the variance mean between the groups is 11544.876 and 285.476 - inside. The calculated (F) value is 40.441 . As for the statistical significance, it is 0.000 (less than 0.05), which indicates that the area of living influences ASD adolescents' state.

Results show that 36 family members indicate the northern area, with arithmetic mean $109.81 ; 30$ - the eastern one with 107.50 mean; 57 - the southern with 107.14 mean; 31 - the western area with 106.10 mean; 140 - the central area with 124.43 mean. families' means in different living areas are statistically significant.

\section{Discussion}

Health care and socialisation of people with special needs are among the essential indicators of social sustainability. Saudi Arabia's Vision 2030 and the 2020 National Transformation Programme aim to raise the country's position 
from 26 to 10 in the Social Capital Index (Alshuwaikhat \& Mohammed, 2017). Engaging adolescents and adults with ADS in social activities are also among the programme's objectives.

Today, more and more studies are appearing on the participation of parents of children with autism in polls. Thus, over a decade ago, according to a survey of parents of 1,200 autistic children in the UK (Siklos \& Kerns, 2007), who displayed the greatest concern about the time that doctors needed to spend to make a diagnosis. Besides, these parents were also concerned about the distance to the location of the medical centre where the diagnosis was going on. Among the significant factors, a connection was established between the first treatment and the final diagnosis. The diagnosis itself caused long periods of emotional and mental decline in the parents, as it took much time due to the long queues and the need for interventions before and after the diagnosis (Notas, 2006; Siklos \& Kerns, 2007). European authors showed that up to half of all parents surveyed (49\% in the UK) were not satisfied with the diagnostic process (Chamak, Bonniau, Oudaya, \& Ehrenberg, 2011). In most cases, the mean age of diagnosis was around 6 , and the number of recorded diagnoses doubled over a 4-year period. Waiting time for the diagnosis is confirmed by another study to be the most important factor (Notas, 2006; Saggu, 2015; Siklos \& Kerns, 2007). According to 29 parents of children with autism, it is necessary to pay attention to the condition of children as soon as possible, so that it will be possible to get a diagnosis at an earlier age and begin treatment accordingly (Barrie, 2010).

Nevertheless, a comparison of the data on autism diagnosis in modern medicine and medicine of the late 20th century made it possible to establish progress: now the average age of children with a diagnosis is three years (Chamak et al., 2011). According to some reports, the more information about the diagnosis and help is received by parents of children with autism, the less pronounced their stress (Osborne \& Reed, 2008). A large study conducted in 5 countries found that the level of education and income of parents directly determines the earlier timing of a child's diagnosis (Goin-Kochel, Mackintosh, \& Myers, 2006). The results of the current research also confirm the importance of this factor, that is, the economic factor - the leading one. In addition, the level of education is also of great importance.

However, the findings on 125 families living in the USA did not establish a connection between the geography of the family's residence (rural areas and cities) but the results demonstrated establishing improvements in the timing of autism diagnosis, as well as its consistency (Gaitonde, 2008). In general, the parents seek to more information and ability to ask questions throughout the autism treatment session (Hasnat \& Graves, 2000).

One of the current findings of the research is the challenges that adolescent ASD patients face vary significantly depending on their places of residence. The level of assistance is reported by parents and doctors in the UK to be approximately the same. Among many forms of assistance under consideration are speech therapy, occupational therapy, behaviour therapy, and other services (Gaitonde, 2008). This suggests that challenges are associated with social and economic factors, rather than the quality of professional assistance. A similar study on quality assessment should have been carried out in KSD in order to obtain a more accurate understanding of challenges across different regions.

The current study's results reflect that economic problems are among the top ones for the families. Psychological problems are rated second. The current study also agrees with the findings of Fayyad (2014). High income helps families adapt to their problems better. Other studies (Qahtani, A., \& Hiyasat, M., 2016) show a significant role of the household income in treating ADS. In particular, families with enough funds can afford diagnosis and ongoing professional assistance and hence, expect better progress on social adaptation. These results 
correspond to those of the observations made by Fayyad (2014).

The current study revealed gender-based differences that are statistically significant. As it turned out, female adolescents experience greater challenges. The factor of gender is seldom addressed and rarely described in other studies, although it remains paramount given the gender equality campaigns that currently take place in the world (Fakeeh, 2016).

Nevertheless, the first challenge the ADS adolescents encounter is financial (that is, the expenditures on treatment), followed by social (that is, the difficulties in the communication). These challenges may be resolved with advanced digital methods of self-diagnosis and self-training, which, in conjunction with behavioural therapy sessions, improve the patient's speech (Chen, Lee \& Lin, 2015). Further research on the effectiveness of and satisfaction with digital auxiliary methods for the treatment of ADS is recommended.

\section{Conclusion}

The current study shows that the most significant are problems of an economic nature, which may depend on the geographical (and political) factor. In developed countries, remoteness from a medical centre may be more important than the availability of the necessary amount of money for treatment, since most often expenses are covered by health insurance.

According to the findings, the researchers recommend the following:

- increasing the number of medical centres for persons with ASD and their families as well as psychological and counselling services;

- establishing educational centres and specific criteria for their evaluation;

- creating associations for sport and recreation that will offer services to adolescents with ASD throughout KSA.

- using this study in education and rehabilitation institutions to make use of it in planning program memos for adolescents with ASD.

\section{References}

Alshuwaikhat, H., \& Mohammed, I. (2017).

Sustainability matters in national development visions-Evidence from Saudi Arabia's Vision for 2030. Sustainability, 9(3), 408. https://doi.org/10.3390/su9030408

Barrie, D. (2010). Factors that influence parents toward early diagnosis of Autism Spectrum Disorder. Unpublished dissertation. Windsor: University of Windsor.

Centre for Adolescent Health (2010). Social and emotional changes in adolescence. The Royal Children's Hospital, Melbourne, Australia.

Retrieved from

https://www.rch.org.au/kidsinfo/fact_sheets/M entalhealthadolescents/

Chamak, B., Bonniau, B., Oudaya, L., \& Ehrenberg, A. (2011). The autism diagnostic experiences of French parents. Autism, 15(1), 83-97.

https://doi.org/10.1177\%2F1362361309354756

Chen, C. H., Lee, I. J., \& Lin, L. Y. (2015).

Augmented reality-based self-facial modeling to promote the emotional expression and social skills of adolescents with autism spectrum disorders. Research in Developmental Disabilities, 36, 396-403.

https://doi.org/10.1016/j.ridd.2014.10.015

Fakeeh, K. A. (2016). KSA 2030 Vision (Kingdom of Saudi Arabia's 2030 project) and its focus on families and students. International Journal of Computer Applications, 149(1), 46-48. https://doi.org/10.5120/ijca2016911345

Fayyad, Q. M. (2014). Problems of mothers whose adolescents with ASD and, Down syndrome. Master thesis. Amman, Jordan: Amman Arab University.

Gaitonde, S. (2008). A survey of parent satisfaction about services for children with pervasive developmental disorder. Unpublished dissertation. Oklahoma: Oklahoma State University.

Goin-Kochel, R. P., Mackintosh, V. H., \& Myers, B. J. (2006). How many doctors does it take to make an autism spectrum diagnosis? Autism, 
10(5), 439-451.

https://doi.org/10.1177\%2F1362361306066601

Hasnat, M. J., \& Graves, P. (2000). Disclosure of developmental disability: A study of parent satisfaction and the determinants of satisfaction. Journal of Paediatrics and Child Health, 36(1), 32-35.

https://doi.org/10.1046/j.1440-

1754.2000.00463.x

Jiménez-Iglesias, A., Moreno, C., Ramos, P., \& Rivera, F. (2015). What family dimensions are important for health-related quality of life in adolescence? Journal of Youth Studies, 18(1), 53-67. https://doi.org/10.1080/13676261.2014.93319 1

Kharaan, H. (2016). Problems of children with ASD and methods of facing them from the perspective of their guardians. Specialized International Journal of Education, 5(1), 1-10.

Notas, S. (2006). Parents and siblings of children with autism. Association of Parents, Guardians and Friends of autistic persons in the prefercture of Larissa.

Osborne, L. A., \& Reed, P. (2008). '"Parents' perceptions of communication with professionals during the diagnosis of autism. Autism, 12(3), 309-324. https://doi.org/10.1177\%2F1362361307089517 Qahtani, A., \& Hiyasat, M. (2016). Life quality of youth with ASD in Riyadh city and its relation to some variables. Journal of Special Education and Rehabilitation, 3(11), 177-207.

Saggu, R. K. (2015). Parental perceptions of the diagnostic process for Autism Spectrum Disorder in British Columbia. Unpublished doctoral dissertation. Minneapolis: College of Social and Behavioural Sciences, Walden University.

Sawyer, S. M., Azzopardi, P. S., Wickremarathne, D., \& Patton, G. C. (2018). The age of adolescence. The Lancet Child \&

Adolescent Health, 2(3), 223-228. https://doi.org/10.1016/S2352-4642(18)300221

Seltzer, M., \& Krauss, M. (2002). Adolescents and adults with autism. A profile of adolescents and adults with autism spectrum disorders. Adolescents and Adults with Autism Report, 2, 1-10.

Siklos, S., \& Kerns, K. A. (2007). Assessing the diagnostic experiences of a small sample of parents of children with autism spectrum disorders. Research in Developmental Disabilities; 28, 9-22.

https://doi.org/10.1016/j.ridd.2005.09.003

Waznah, T. (2011). Autism demography in KSA: a statistical study on the disabled registered at the ministry of labor and social affairs.

Zaghareer, A. A. (2009). Sources of psychological pressures and methods of facing them from the perspective of guardians of children with ASD in Jordan and their relation to some variables. Unpublished MA Thesis.

Amman Arab University for Higher Studies: Jordan.

\section{Acknowledgements}

This research project was funded by the Deanship of Scientific Research, Princess Nourah Bint Abdulrahman University, through the Research Funding Program, grant No (39- S-247). 